\title{
PENA Y CIUDADANIA
}

Juan Pablo Mañalich $\boldsymbol{R}^{*}$

INTRODUCCION; 1. La pena en el estado democrático de derecho: culpabilidad material y lealtad comunicativa; 2. La función expresiva de la pena; 3. Reproche, reconocimiento y ciudadanía; 4. Privación de ciudadanía y privación de libertad; 5. La constitución del derecho penal del enemigo.

\section{INTRODUCCION}

La historia de la locura sería la historia de lo Otro - de lo que, para una cultura, es a la vez interior y extraño y debe, por ello, excluirse (para conjurar un peligro interior), pero encerrándolo (para reducir la alteridad) [...].1

De este modo sugería Foucault la correspondencia entre el proyecto de escribir una historia del orden de las cosas (que lleva al aparecimiento de las "ciencias humanas") y el proyecto de escribir una historia de la locura, ${ }^{2}$ que es la correspondencia que en el nivel del objeto se da entre la constitución de lo Mismo y la constitución de lo Otro. Si es acertada la representación del hospital y de la prisión como instituciones fundadas en una misma técnica disciplinaria, ${ }^{3}$ entonces cobra fuerza la hipótesis de que la pena de privación de libertad también funciona excluyendo y encerrando "lo Otro". Pero si se mantiene la correlación entre internación terapéutica y pena privativa de libertad, la distinción entre penas y medidas de seguridad se vuelve impracticable.

Sostengo la tesis de que bajo una organización democrática de la práctica punitiva, la imposición de la pena sólo puede justificarse retrospectivamente, como un reproche institucionalizado por un déficit de fidelidad al derecho, de modo que ella no puede implicar la negación de reconocimiento a quien la sufre. Si la pena privativa de libertad se constituye como una práctica de exclusión, ella es incompatible con el reconocimiento implicado en el reproche de culpabilidad. Esta contradicción se hace explícita, en el marco del derecho chileno vigente, en el hecho de que la imposición de una pena aflictiva implique la pérdida de la ciudadanía. Bajo una justificación democrática de la pena, un sujeto condenado por un hecho punible debe conservar su condición de ciudadano, pues la

\footnotetext{
* Abogado, Facultad de Derecho, Universidad de Chile. Profesor de derecho, Universidad Adolfo Ibáñez.

${ }^{1}$ Foucault, Las Palabras y las Cosas (Siglo XXI: Buenos Aires, 1968) p. 9.

${ }^{2}$ Este último proyecto fue llevado a cabo en sus dos tomos de la Historia de la Locura en la Época Clásica (FCE: México, 1976).

${ }^{3}$ Foucault, Vigilar y Castigar (Siglo XXI: Madrid, 1976, 2000) pp. 175 ss.
} 
legitimidad (de las consecuencias) del reproche que se expresa en la pena presupone su reconocimiento como miembro de la comunidad política.

\section{La pena en el estado democrático de derecho: culpabilidad material y lealtad comunicativa}

Bajo una teoría del delito entendida como teoría de la imputación, ${ }^{4}$ el hecho punible se reconstruye como un acto expresivo. El autor manifiesta, a través de su comportamiento, que la norma que prohíbe ese comportamiento no vale para él. ${ }^{5} \mathrm{El}$ objeto de referencia inicial, por ende, está constituido por una norma de comportamiento, que establece como prohibida una determinada forma de conducta (activa u omisiva). Desde el punto de vista de su función prospectiva, la norma de comportamiento puede ser vista como una directiva de conducta. Mirando el establecimiento de la norma como un acto de habla, su sentido ilocucionario consiste en proveer una razón para la acción. Quien contraviene la norma de comportamiento sin reconocerla como una razón para la acción, niega que la norma sea una razón que lo vincule. El reproche penal presupone, entonces, una vinculación entre el sujeto y la norma. La medida de esta vinculación se fija en atención a determinadas reglas de imputación, las cuales establecen las condiciones bajo las cuales un sujeto puede ser considerado responsable por un comportamiento prohibido por una norma. La imputación del comportamiento incorrecto a la capacidad del sujeto de evitarlo y de motivarse a evitarlo es condición necesaria y suficiente de su sentido expresivo como desautorización de la norma.

La imputación puede descomponerse en dos niveles. ${ }^{6}$ En un primer nivel, se trata de la imputación del comportamiento a la capacidad (puramente fáctica) de evitación. Esto exige la constatación de capacidad de acción en el sujeto, entendida como capacidad de formarse una intención de realizar el comportamiento exigido por la norma de comportamiento (suponiéndose contrafácticamente la motivación de actuar con arreglo a la norma), lo cual supone cierto grado de control corporal (que falta en los casos tradicionales de ausencia de acción: inconsciencia, vis absoluta, etc.) y cierto grado de conocimiento de la situación en que el sujeto se encuentra (que falta en los casos de ausencia de dolo, siquiera eventual). ${ }^{7}$ En el

\footnotetext{
${ }^{4}$ Para una distinción entre teorías del delito como teorías de la imputación y teorías del delito como teorías de la infracción, Silva Sánchez, “¿Directivas de conducta o expectativas institucionalizadas? Aspectos de la discusión actual sobre la teoría de las normas", en Normas y acciones en Derecho penal (Hammurabi: Buenos Aires, 2003) pp. 15-39, 33-6.

5 Este modelo se encuentra desarrollado en Kindhäuser, Gefährdung als Straftat (Vittorio Klostermann: Frankfurt a.M, 1989) pp. 29-131; Vogel, Norm und Pflicht bei den unechten Unterlassungsdelikten (Duncker \& Humblot: Berlín, 1993) pp. 27-92.

${ }^{6}$ Hruschka, "Reglas de comportamiento y reglas de imputación", XLVII Anuario de Derecho Penaly Ciencias Penales (Madrid, 1994) pp. 343-56.

${ }^{7}$ La falta de algún presupuesto de la capacidad de acción puede no obstar a la imputación, en la medida en que esa falta pueda ser achacada al propio sujeto. Esto es posible en la medida en que el
} 
segundo nivel, se trata de la imputación a la capacidad de motivación del sujeto, entendida como la capacidad de formarse una intención (de segundo orden), con base en la norma de comportamiento, de realizar intencionalmente el comportamiento exigido por ésta, capacidad que se excluye si el sujeto no tiene la madurez suficiente para orientar su conducta bajo una norma (incapacidad de culpabilidad o inimputabilidad), o si el sujeto no conoce la norma (error de prohibición), o si una motivación conforme con la norma, aunque posible, resulta inexigible (estado de necesidad exculpante, miedo insuperable, etc.). En el primer nivel de imputación, se supone -contrafácticamente- la motivación de evitar la realización del comportamiento prohibido, de modo que habiendo capacidad de acción, esto es, capacidad de formarse una intención de evitar, se afirma que el sujeto podía evitar la realización del comportamiento prohibido, de modo que el comportamiento se le imputa como contrario a deber y, por ende, como "injusto". En el segundo nivel de imputación, se considera si el sujeto podía efectivamente motivarse a actuar con arreglo a esa razón, de modo que al sujeto pueda reprocharse la realización del comportamiento prohibido. Esta imputación de segundo nivel representa la imputación a la culpabilidad. Quien se decide a favor de un comportamiento definido como prohibido habiéndose podido formar la intención de evitar la realización de ese comportamiento (o sea, teniendo una alternativa de acción), pone de manifiesto, en la terminología de Rawls, una falta de sentido de la justicia. El reproche de culpabilidad, a su vez, consiste en el reproche por la toma de posición, en el nivel de la formación de una intención de segundo orden, a favor de lo injusto. ${ }^{8}$

Esta construcción de las condiciones de la punibilidad presupone que la norma de comportamiento pueda considerarse una razón vinculante para la acción, cuya falta de reconocimiento pueda justificar el reproche implicado en la imputación. Esto sólo es posible en la medida en que se valide una expectativa de fidelidad al derecho, lo cual validaría la definición de la culpabilidad material como un déficit de fidelidad al derecho. La pregunta se encuentra referida, por ende, a la validez de la pretensión de fidelidad al derecho, que es una pregunta política. Actualmente, esta posibilidad es mantenida sobretodo bajo una reformulación de la falta de fidelidad al derecho como un déficit de lealtad comunicativa, en el entendido que la validez de la pretensión de fidelidad al derecho puede resultar de la reconducción de la norma de comportamiento a la libertad comunicativa del sujeto. En la doctrina penal alemana actual, este proyecto ha sido emprendido sobre la base de la teoría de la acción comunicativa de Habermas, que hace posible una fundamentación ético-discursiva de normas con una pretensión de validez

déficit se deba a un desvío de un estándar de cuidado exigible, lo cual fundamenta la imputación a imprudencia. En este sentido, se habla de la imprudencia como una forma de imputación "extraordinaria". Lo mismo puede decirse, sobretodo en el segundo nivel de imputación, de la actio libera in causa.

8 Véase Rawls, Teoría de la Justicia (FCE: México, 1979, 1995) pp. 55-9, 177-84; Kindhäuser, Gefährdung als Straftat, pp. 153-60; Vogel, Norm und Pflicht bei den unechten Unterlassungsdelikten, p. 65. 
(corrección o adecuación) intersubjetiva. Así, el punto de partida establecido por Kindhäuser:

[...] no hay, en una sociedad secularizada y pluralista, fundamentos sustanciales a priori para legitimar las normas que regulan el comportamiento. De ahí que la legitimidad solamente pueda ser deducida de la autonomía de los partícipes en el proceso de integración social. ${ }^{9}$

La autonomía del participante que fundamenta la legitimidad de la expectativa de fidelidad al derecho se constituye en la interacción de dos dimensiones de autonomía: la autonomía pública y la autonomía privada. Autonomía pública y autonomía privada se entrecruzan en la constitución de la autonomía comunicativa, que condiciona la posibilidad de vincular al sujeto a la norma (de comportamiento) como su destinatario, en tanto la norma puede ser reconducida al propio sujeto como interviniente (potencial) en el procedimiento de su establecimiento. ${ }^{10}$

La atribución de libertad comunicativa se corresponde con la configuración de lo que Klaus Günther denomina persona deliberativa. ${ }^{11}$ Es persona deliberativa aquella a la cual se reconoce libertad comunicativa, que puede entenderse como capacidad crítica, esto es, como la capacidad de tomar posicionamiento crítico, tanto frente a manifestaciones y acciones ajenas como frente a manifestaciones y acciones propias. El carácter crítico de la toma de posición se afirma en la medida en que ella sea apoyada en razones. Según Günther, las razones se definen por el hecho de que ellas "hacen una diferencia en el mundo, en tanto pueden motivar a una persona a la revisión y modificación de sus manifestaciones y acciones". ${ }^{12}$

En su componente de autonomía pública, la libertad comunicativa de la persona deliberativa la posiciona como ciudadano del estado, de modo que la capacidad de participar en el procedimiento de establecimiento de normas, tomando posición crítica frente a los actos de justificación de normas, hace posible reconducir éstas a la autonomía del ciudadano. Esta reconducción de la norma a la autonomía de la persona deliberativa en tanto ciudadano es lo único que justifica la pretensión de vinculación a la norma que puede dirigirse contra la persona deliberativa que, en la dimensión de autonomía privada de la libertad comunicativa, se posiciona como persona de derecho (Rechtsperson), esto es, como destinatario de la norma. ${ }^{13}$

Es fundamental advertir la relación precisa entre la atribución de personalidad deliberativa y la obligación de seguir la norma que legitima el

\footnotetext{
${ }^{9}$ Kindhäuser, "La fidelidad al derecho como categoría de la culpabilidad", en 1 Revista Peruana de Doctrina y Jurisprudencia Penal (Lima, 2000) pp. 171-213, 194-5.

10 ibid 196.

${ }^{11}$ Günther, Schuld und kommunikative Freiheit (Vittorio Klostermann: Frankfurt a.M, 2005) pp. 245-6.

12 ibid.

13 ibid 249 ss; Habermas, Facticidady V alidę.(Trotta: Madrid, 1998) pp. 186-7.
} 
reproche por la ejecución del comportamiento prohibido. En especial, ha de enfatizarse la diferencia entre discurso y procedimiento democrático, pues sólo de ese modo puede darse cuenta de la posibilidad mediadora entre facticidad y validez que cabe atribuir al derecho. ${ }^{14} \mathrm{El}$ procedimiento democrático está organizado de modo tal que posibilita, en cierto espacio de tiempo, decisiones mayoritarias sobre la validez positiva de normas jurídicas. Esto implica que las normas jurídicas, democráticamente establecidas, también rigen respecto de sujetos que no han hecho uso de su capacidad de autonomía pública:

De esto se deriva que la persona deliberativa, la cual tiene un derecho subjetivo de participación política, no está obligada a hacer uso fáctico de la capacidad atribuida de posicionamiento crítico como participante en discursos públicos. ${ }^{15}$

Antes bien,

El deber de cada ciudadano del estado al seguimiento de la norma se fundamenta sólo en su igual derecho al ejercicio público de su capacidad crítica y en el procedimiento jurídicamente institucionalizado en el cual este derecho puede ser ejercido $-\mathrm{y}$ no, en cambio, en el si y como ni en el resultado del ejercicio de este derecho. ${ }^{16}$

Por esto, el destinatario de la norma puede decidir si y por qué razón ha de seguir la norma. Un cumplimiento de la norma motivado por consideraciones de racionalidad puramente estratégica, esto es, un seguimiento puramente prudencial de la norma, no justifica reproche alguno. Dentro del acuerdo expresado en las normas jurídicas vigentes, a la persona de derecho cabe reconocer una libertad instrumental. En esto consiste el mandato de neutralidad que el derecho no puede desconocer en su pretensión de vincular al sujeto a la comunidad. ${ }^{17} \mathrm{La}$ conminación legal de la sanción, esto es, el anuncio de la imposición de la pena contenida en las normas de sanción de la ley penal, ha de considerarse una consecuencia del mandato de neutralidad: el estado reconoce la posibilidad de que el destinatario de la norma no la siga como consecuencia de un ejercicio de capacidad de crítica conducente al asentimiento, sino que la siga exclusivamente motivado por la ventaja de evitar la sanción. ${ }^{18}$ A la inversa, el reproche sólo se justifica cuando en la realización del comportamiento el sujeto no reconoce la norma, en la medida que el sujeto, como persona deliberativa, pudo participar como ciudadano en el procedimiento de adopción de la norma. Por eso, la

\footnotetext{
14 ibid.

${ }^{15}$ Günther, Schuld und kommunikative Freibeit, p 250.

16 ibid 251.

${ }^{17}$ Kindhäuser, "La fidelidad al derecho como categoría de la culpabilidad”, pp. 198, 202, 205.

18 Günther, Schuld und Kommunikative Freiheit, p. 252; Habermas, Facticidad y Validez, pp. 177-8. El mandato de neutralidad impide fundamentar la culpabilidad material como autocontradicción del autor como sujeto racional al modo kantiano, pero también como la autocontradicción del sujeto como ciudadano en el sentido tradicional del comunitarismo. Véase Kindhäuser, "La fidelidad al derecho como categoría de la culpabilidad", pp. 172-85.
} 
exigencia de legalidad de la norma de comportamiento cumple la función inversa a la de la exigencia de legalidad de la norma de sanción: mientras que el establecimiento legal de la norma de sanción es reconocimiento de libertad instrumental, en el establecimiento legal de la norma de comportamiento se expresa formalmente su característica de resultado del proceso democrático, de modo que la norma puede ser atribuida al ejercicio de la libertad comunicativa en su faz de autonomía pública. Por eso, en el nivel de la norma de comportamiento el principio de legalidad no puede ser entendido como un criterio de limitación, sino sólo como una condición constitutiva del carácter vinculante de la norma.

El modelo requiere asumir, sin embargo, que la conexión interna entre la condición de ciudadano y la condición de persona de derecho no puede interpretarse como una equiparación. Como ciudadano, la persona deliberativa tiene derecho a rechazar la norma y a participar en el procedimiento democrático abogando por su supresión o modificación. Pero la persona deliberativa no puede invocar este derecho cuando, en su rol de persona de derecho, se encuentra en una situación en que está obligada a seguir la norma. ${ }^{19} \mathrm{Si}$ la persona de derecho abandona el ámbito de libertad instrumental acordado y que se expresa en las normas de comportamiento vigentes en tanto reglas que coordinan ámbitos de autonomía, queda vinculada por una obligación de lealtad comunicativa: el rechazo del acuerdo debe justificarse en el marco del procedimiento institucional disponible para su revisión. ${ }^{20}$ Como afirma Günther, "el estado democrático de derecho vive del cambio regulado e institucionalizado entre los roles de ciudadano y persona de derecho". ${ }^{21}$ La lealtad comunicativa, como correlato de la libertad comunicativa atribuida a la persona deliberativa, consiste en no arrogarse unilateralmente ese cambio de roles.

Esto puede hacer surgir algunas dificultades. ¿Cómo justificar, sobre esta base, la posibilidad de un reproche penal en contra de sujetos que, por determinadas razones, no son ciudadanos, por ejemplo, los extranjeros? La respuesta exige identificar que no es la mera posibilidad de emitir un voto lo que constituye la posibilidad de vinculación entre norma y sujeto, precisamente porque el proceso democrático no puede ser reducido al acto de emisión del voto. Lo que se expresa en el derecho de sufragio es el proyecto político que es constitutivo de la democracia, a saber, el proyecto del autogobierno. Las normas democráticamente producidas son normas que, de esa manera, pueden ser entendidas como normas que son producto de la autonomía pública que compete al ciudadano, que de ese modo es destinatario de las normas en su calidad de persona de derecho a la cual compete autonomía privada. En el caso de los extranjeros, la condición de ciudadano como sujeto al cual se reconoce autonomía pública, ciertamente aparece mermada. Esto es compensado, por una parte, con la posibilidad de que bajo ciertas condiciones el extranjero pueda tomar parte en el

\footnotetext{
${ }^{19}$ Günther, Schuld und kommunikative Freibeit, p. 252.

${ }^{20}$ Kindhäuser, "La fidelidad al derecho como categoría de la culpabilidad", pp. 198-9.

${ }^{21}$ Günther, Schuld und kommunikative Freiheit, p. 253.
} 
proceso democrático, lo cual se expresa en (pero no se reduce a) la extensión del derecho de sufragio. Pero por otra parte, es obvio que la expectativa de fidelidad al derecho, o sea, de lealtad comunicativa en la dimensión de la autonomía privada, también se ve reducida frente a extranjeros. Desde este punto de vista, no es casual la mayor viabilidad de la afirmación de un error de prohibición (directo) invencible que excluya la culpabilidad del sujeto en razón de su condición extranjero. Que se excluya la culpabilidad no significa otra cosa que el reconocimiento de la improcedencia de un reproche por déficit de fidelidad al derecho. La alegación del carácter heterónomo de la norma tiene mucha mayor plausibilidad tratándose de un sujeto que es ajeno a la comunidad democráticamente organizada.

Lo anterior podría arrojar algo de luz, además, sobre el debate acerca de la reducción del mínimo de edad requerido para la imputabilidad, o sea, para la capacidad de culpabilidad. El mínimo de edad que condiciona la culpabilidad es el mínimo de edad que es compatible con la formulación de un reproche que se basa en actitudes reactivas de desaprobación y decepción. Esto no implica, ciertamente, que haya un criterio que haga posible fijar, de modo no controvertido, cuál ha de ser esa edad. Pero sí pone de manifiesto lo problemática de la aproximación al problema bajo un punto de vista preventivo. La imputabilidad determina el margen a partir del cual un sujeto es reconocido como posible destinatario de un reproche por falta de lealtad comunicativa. Esto presupone su reconocimiento como participante en la acción comunicativa, o sea, en los contextos en que buscamos entendernos unos con otros. Las razones por las cuales no se reconoce autonomía pública a los menores de edad son razones para poner en duda la plausibilidad de constituirlos en destinatarios de reproche en el plano de su autonomía privada, sobretodo si se trata de un reproche que es idéntico al de aquellos sujetos de los cuales cabe esperar lealtad comunicativa. Ciertamente, la cuestión no puede ser planteada ni resuelta en términos binarios, de todo o nada. Pero si autonomía pública y autonomía privada son correlativas, o sea, sinalagmáticas, un déficit de autonomía pública se corresponde con un déficit de autonomía privada. Y ésta no es una razón para instrumentalizar teleológicamente el reconocimiento de autonomía pública para legitimar el reconocimiento instrumental de autonomía privada y, por ende, la sujeción de los menores al derecho penal de adultos, sino para resistir esa instrumentalización.

\section{La función expresiva de la pena}

Si la imputación a la culpabilidad se entiende como un reproche por una falta de lealtad comunicativa, ha de ponerse en duda la plausibilidad de una justificación (directamente) prevencionista de la pena. Esto se debe a que el reproche de culpabilidad se corresponde con la adopción de una actitud reactiva, que es incompatible con el mantenimiento de una actitud objetivante respecto del sujeto a quien se reprocha la decisión por la conducta incorrecta. La reprobación, como el resentimiento, es una actitud reactiva, que forma parte de nuestra experiencia cotidiana, y la cual presupone la participación en relaciones 
interpersonales con otros, y en particular la consideración del destinatario del reproche como un participante en la comunicación. ${ }^{22}$ Si la práctica punitiva está fundada sobre esta clase de actitudes reactivas, lo cual parece formar parte de la definición de un derecho penal de la culpabilidad, resulta imposible dar cuenta de esa práctica prescindiendo de esas actitudes. Por esto Strawson, aunque afirma que puede tener sentido discutir sobre la eficacia de este tipo de prácticas, agrega:

Lo que sí es un error es olvidar que estas prácticas, el modo en que las recibimos -las reacciones ante ellas- son realmente expresiones de nuestras actitudes morales y no meramente mecanismos que empleamos de forma calculada con fines regulativos. ${ }^{23}$

La incompatibilidad entre el reproche que se funda en una actitud reactiva y la adopción de una actitud objetivante radica en que esto último implica ver al otro como un "objeto de táctica social", como un individuo que ha de ser sujeto a tratamiento, respecto del cual hay que adoptar, eventualmente medidas preventivas. ${ }^{24} \mathrm{La}$ adopción de una actitud reactiva, y aun la irrogación de un mal como consecuencia, en cambio, supone que al sujeto se lo sigue considerando miembro de la comunidad, puesto que "tales actitudes de desaprobación e indignación son precisamente los correlatos de la demanda moral cuando se siente que la demanda ha sido ignorada". ${ }^{25}$

Es en este sentido, que todavía debe ser precisado, que el reproche de culpabilidad implica un reconocimiento del sujeto a quien el hecho se imputa como culpable: como participante potencial en la interacción orientada al entendimiento, o sea, como participante en la acción comunicativa. ${ }^{26}$ Por eso, una concepción de la pena como acto expresivo no supone asumir como correcta la dialéctica de la negación que subyace a la justificación idealista de la pena como negación de la negación del derecho (que es el sentido que tiene el delito). Antes bien, el reproche de culpabilidad sólo entraña una oferta incondicionada de comunicación entre el estado y el autor, que es el único que puede restablecer el reconocimiento de la norma negada. El mandato de neutralidad impide, ahora en el nivel de la imposición de la pena, que el estado exija o fuerce ese reconocimiento. ${ }^{27}$ Como sostiene Günther, la diferencia específica entre el reproche penal de culpabilidad y una asunción moral de culpabilidad se encuentra en la perspectiva bajo la cual se formula el reproche, o sea, en el nivel ilocucionario del acto y no en su contenido proposicional: el reproche penal de culpabilidad se formula en tercera persona. Y ésta es una exigencia cuya observancia es imprescindible para el mantenimiento de la distinción entre derecho y moral. ${ }^{28}$ Lo

\footnotetext{
22 Strawson, Libertady resentimiento (Paidós: Barcelona, 1995) p. 47.

23 ibid 67.

24 ibid 46-7.

25 ibid 63.

${ }^{26}$ Kindhäuser, "La fidelidad al derecho como categoría de la culpabilidad", p. 210.

27 ibid 209-12.

${ }^{28}$ Günther, Schuld und kommunikative Freiheit, pp. 95-8
} 
fundamental es, en todo caso, que si la facticidad (de la imposición y la ejecución) de la pena ha de subordinarse a su función expresiva, ${ }^{29}$ el objeto de la oferta al sujeto sólo puede verse como la asunción de la pena "como reacción simbólica frente a la defraudación producida por la deslealtad de su comportamiento". 30

A esta concepción de la pena seguramente se objetará su compromiso con la idea de retribución. Son ya clásicas las referencias a que en un estado de derecho, la pena sólo puede justificarse por su utilidad, lo cual paradigmáticamente remite a alguna variante de teoría prevencionista. Así por ejemplo, en la defensa de su teoría dialéctica de la unión, Roxin mantiene que la culpabilidad no puede constituir una razón suficiente para la imposición de la pena, en el entendido de que

[...] la posibilidad de culpabilidad humana presupone la libertad de voluntad (el libre albedrío), y su existencia, como conceden incluso los partidarios de la idea de retribución, es indemostrable. ${ }^{31}$

Esto lleva a que Roxin defienda una concepción unilateral del principio de culpabilidad, en términos de que la culpabilidad sólo puede considerarse condición necesaria, pero no (necesaria y) suficiente de la imposición de la pena (como se mantiene bajo una concepción bilateral). ${ }^{32}$

Contra esto ha de plantearse, primero, que la tesis del determinismo no alcanza justificar que la práctica del castigo (estatal) no pueda estar fundada en la adopción de actitudes reactivas como el resentimiento, la desaprobación y el reproche. Pues éste es precisamente el punto de Strawson: un rechazo de la metafísica del libre albedrío no implica dejar de reconocer que algunas prácticas humanas están organizadas sobre la base de la expresión de actitudes reactivas, y que esta expresión de actitudes reactivas tiene sentido frente a acciones que, en tanto eventos descritos en términos de lo mental, pueden ser tratadas como libres.

Aun aceptando una tesis monista respecto de la relación entre eventos físicos y eventos mentales, esto es, la afirmación de identidad entre cada evento mental y un evento físico correspondiente, es posible entender que la explicación nomológica (en base a leyes causales) de una cadena de eventos es dependiente de la descripción de esos eventos como físicos. Pero si los eventos son descritos en el "lenguaje de lo mental", se hace imposible su explicación nomológica con arreglo a leyes causales, pues lo distintivo de lo mental es la inexistencia de leyes que hagan posible predecir y explicar los eventos descritos de este modo,

\footnotetext{
${ }^{29}$ La terminología procede de Feinberg, "The Expressive Function of Punishment", en Doing and Deserving (Princeton University Press: Princeton, 1970).

${ }^{30}$ Kindhäuser, "La fidelidad al derecho como categoría de la culpabilidad", p. 211.

31 Roxin, "Sentido y límites de la pena estatal", en Problemas básicos del derecho penal (Reus: Madrid, 1976) pp. 11-36, 13.

32 Véase Roxin, "Concepción bilateral y unilateral del principio de culpabilidad", en Culpabilidad y prevención en derecho penal (Reus: Madrid, 1981) pp. 187-200.
} 
independientemente de que sí existan leyes que harían posible su explicación si fuesen descritos como eventos físicos. La descripción de un evento como una acción conlleva el uso de ciertos términos que inequívocamente apelan a lo mental, desde ya si se recurre una teoría de la acción intencional ${ }^{33}$. Entre eventos físicos y mentales cabe, entonces, mantener una posición monista (o sea, de identidad), pero al mismo mantener el carácter anómalo (no sujeto a leyes) de esa relación de identidad. En este consiste la tesis davidsoniana del monismo anómalo. ${ }^{34}$

Por otra parte, la tesis de que la justificación prevencionista de la práctica punitiva constituiría una exigencia moderna de racionalidad supone asumir un concepto de racionalidad puramente estratégica, que tiene un compromiso con un escepticismo moral en cuanto a la posibilidad de fundamentación de expectativas de conducta intersubjetivamente válidas. En la ética del discurso, desvinculada de toda pretensión de fundamentación última, ${ }^{35}$ se encuentra una vía de refutación del escéptico que hace posible vislumbrar las bases de una normatividad con pretensión universal no comprometida metafísicamente. Y la ética del discurso está construida sobre una concepción no estratégica sino comunicativa de la racionalidad, esto es, sobre una concepción de la racionalidad como orientación al entendimiento en la comunicación. En términos de la teoría de los actos de habla,

${ }^{33}$ En este sentido, Davidson, Essays on Actions and Events (Oxford University Press: Oxford, 2001) pp. 43-81.

34 Ibid 205-59.

35 El núcleo de la ética del discurso se encuentra en la pretensión de identificación de ciertos presupuestos del habla que, según Habermas, pueden ser representados en la forma de reglas de argumentación, algunas de las cuales tienen contenido normativo, de modo tal que el participante en el diálogo que niega tales presupuestos incurre en una contradicción realizativa (o "performativa"). A partir de la identificación de estos presupuestos inevitables de la argumentación, podría fundamentarse el postulado de la universalidad, conforme al cual una norma (polémica) puede considerarse justificada, esto es, válida, "cuando todo pueden aceptar libremente las consecuencias y efectos colaterales que se producirán previsiblemente del cumplimiento general de una norma polémica para la satisfacción de los intereses de cada uno". Este postulado de universalidad, que pertenece a la lógica del discurso, debe diferenciarse del postulado de la ética del discurso, según el cual "únicamente pueden aspirar a la validez aquellas normas que consiguen (o puedan conseguir) la aprobación de todos los participantes en cuanto participantes de un discurso práctico". Habermas, "Etica del discurso. Notas sobre un programa de fundamentación", en Conciencia Moral y Acción Comunicativa (Península: Barcelona, 1998) pp. 57-134, 116-7. Asimismo Apel, "La ética del discurso como ética de la responsabilidad. Una transformación postmetafísica de la ética de Kant", en Teoría de la verdad y ética del discurso (Paidós: Barcelona, 1991) pp. 147-84. La divergencia más notable entre ambos planteamientos se refiere al significado del carácter inevitable de los presupuestos del habla a partir de los cuales puede derivarse el postulado de la ética del discurso. Según Apel, los presupuestos inevitables del habla son presupuestos necesarios y universales, cuyo carácter normativo posibilita fundamentar directamente, de modo pragmáticotrascendental (esto es, mediante el argumento de la contradicción performativa), normas válidas para ámbitos ajenos al propio discurso. Para Habermas, en cambio, esa fundamentación sólo puede ser indirecta, pues el carácter inevitable de los presupuestos del habla sólo puede implicar falta de alternativas a, pero no una fundamentación última de, las reglas de argumentación correspondientes. Habermas manifiesta, por ende, un compromiso falibilista, que es expresión de racionalismo crítico. 
la orientación al entendimiento puede entenderse como la disposición a la obtención de un acuerdo entre hablante y oyente, lo cual presupone que el hablante sólo persigue el éxito ilocucionario de su acto de habla, lo cual a su vez requiere que el oyente reconozca la pretensión de validez entablada por el hablante, pudiendo entonces tomar posición crítica de aceptación o de rechazo frente a ella. La orientación al entendimiento es incompatible con la acción estratégica, en la cual supone el hablante persigue la producción de efectos perlocucionarios en el oyente, de modo que las bases lingüísticas del entendimiento son instrumentalizadas en interés propio. ${ }^{36}$ Una justificación (directamente) prevencionista de la pena presupone una concepción estratégica de la racionalidad: la intimidación de terceros (prevención general) o la corrección del condenado (prevención especial) pueden entenderse como efectos perlocucionarios de la imposición de la pena. ${ }^{37}$

Esto no implica que la pena no pueda desplegar, indirecta o mediatamente, un efecto preventivo. Esto puede mantenerse en la medida en que se plantee correctamente la relación que hay entre la norma de comportamiento y la norma de sanción. Las normas de sanción de la parte especial pueden entenderse como reglas de adjudicación que condicionan la imposición de una sanción a la verificación de un supuesto de hecho. ${ }^{38}$ La norma de comportamiento puede entenderse como una prohibición de realizar aquellas formas de comportamiento que satisfacen el supuesto de hecho de la norma de sanción. La realización del supuesto de hecho, empero, no es condición suficiente para la aplicación de la sanción, pues ésta presupone la satisfacción de las condiciones bajo las cuales puede imputarse el comportamiento prohibido a la responsabilidad del sujeto, condiciones que están establecidas por las reglas de la imputación de la parte general. ${ }^{39}$ La imposición de la sanción (pena), entendida como institucionalización de la expresión de reproche por la falta de lealtad comunicativa implicada en la falta de reconocimiento de la norma, presupone la vigencia de ésta como vinculante, y de este modo puede contribuir a su reforzamiento simbólico. ${ }^{40}$ Ésta constituye la mejor versión de la teoría de la prevención general positiva, reformulada como teoría de la retribución relativa. La pena sólo puede legítimamente imponerse cuando ella se presenta como un mal que expresa la decepción por el quebrantamiento de la confianza en la observancia de la norma

\footnotetext{
${ }^{36}$ Habermas, Teoría de la acción comunicativa (Taurus: Madrid, 1999) tomo I, pp. 367-78.

37 Así, Mañalich, "El secuestro como delito permanente frente al DL de amnistía", 5 Revista de Estudios de la Justicia (Santiago, 2005) pp. 11-33, 26.

${ }^{38}$ Hart, El Concepto de Derecho (Abeledo Perrot: Buenos Aires, 1963) p. 121.

${ }^{39} \mathrm{La}$ punibilidad de la tentativa, que hace posible la imposición de una sanción a pesar de la noverificación (al menos completa) del supuesto de hecho que se corresponde con la descripción del comportamiento prohibido, muestra que la verificación de un comportamiento antinormativo ni siquiera constituye una condición necesaria de la punibilidad.

${ }^{40}$ En este sentido, Robinson y Darley, "The Utility of Desert", 91 Northwestern Law Review (1996) pp. 453 ss.
} 
de comportamiento (legitimada prospectivamente, como modo de aseguramiento de bienes jurídicos) por parte del sujeto reconocido como agente moral. ${ }^{41}$

La subordinación de la facticidad de la pena a su función expresiva de manifestación de decepción exige invertir la concepción funcional de la culpabilidad defendida, sobretodo, por Jakobs. ${ }^{42}$ No es la culpabilidad la categoría que debe ser definida de modo funcional o a los fines de la pena, sino que es la configuración de la pena la que debe sujetarse a su función expresiva de reproche institucionalizado. Así, Kindhäuser:

[...] tampoco se puede acoplar al reproche de culpabilidad mismo finalidades de la pena. No se puede reprochar a alguien por su comportamiento, sólo con fines de educación, de intimidación, etc. Quien reprocha con base en determinados fines, afecta y niega con ello la autonomía comunicativa del autor del delito. ${ }^{43}$

Pues, parafraseando a Strawson, si la actitud mantenida frente a otro es objetivante, aunque pueda reprochársele algo, no se tratará de un reproche, sino que, a lo sumo, se fingirá que se le está reprochando. ${ }^{44}$ Lo que aquí aparece es el carácter excluyente que tiene una justificación retrospectiva de la pena, entendida como expresión de reproche. En términos de una defensa de una justificación retribucionista de la pena, esto se explica por una tensión irresoluble entre prevención y retribución, que descansa en la incapacidad de cualquier variante de justificación retribucionista de compartir espacio con una justificación alternativa.

Como lo expresa Michael Moore, "en la medida en que alguien es penado por razones distintas a que merece ser penado, la justicia retributiva no es alcanzada" 45 .

Esto ha de tener consecuencias en la configuración de la aplicación de la pena. La irrogación del mal que es la imposición y ejecución de la pena, puede entenderse como una suspensión de una disposición generalmente favorable respecto del sujeto que defrauda la pretensión fijada en la norma. La medida de esta suspensión depende tanto de la magnitud de la lesividad del hecho como de la intensidad de la responsabilidad del sujeto por el hecho lesivo. En términos de las categorías dogmáticas correspondientes, la magnitud del reproche ha de depender

\footnotetext{
${ }^{41}$ Kindhäuser, "Personalität, Schuld und Vergeltung", Goltdammer's Archiv für Strafrecht (1989) pp. 493-507, 502-4.

${ }^{42}$ Jakobs, “Culpabilidad y prevención”, en Estudios de Derecho Penal (Civitas: Madrid, 1997) pp. 7399.

43 Kindhäuser, "La fidelidad al derecho como categoría de la culpabilidad", p. 213.

${ }^{44}$ Strawson, Libertad y resentimiento, p. 47: "Si la actitud de usted hacia alguien es totalmente objetiva entonces, aunque pueda pugnar con él, no se tratará de una riña; y aunque le hable e incluso sean partes opuestas en una riña de negociación, no razonará con él. A lo sumo, fingirá que está riñendo o razonando".

${ }^{45}$ Moore, Placing Blame (Oxford University Press: Nueva York, 1997) p. 28.
} 
tanto de las características de la antinormatividad del comportamiento como de la culpabilidad del autor. ${ }^{46}$ Pero esto no puede restringirse al quantum de la pena privativa de libertad o de multa eventualmente aplicable. La exigencia de funcionalidad de la consecuencia institucional del reproche a su sentido comunicativo tiene que extenderse también a las consecuencias accesorias asociadas jurídicamente al reproche. Pues algunas de éstas tocan el núcleo de la pregunta por el reconocimiento que subyace a la imposición de la pena tras la condena.

\section{Reproche, reconocimiento y ciudadanía}

El reconocimiento implicado en la declaración de la culpabilidad no puede entenderse como que el autor del delito tenga un derecho a la pena. ${ }^{47}$ Antes bien, el reconocimiento está dado por el hecho de que el reproche supone considerar al sujeto como vinculado por la norma, y esto supone una atribución de la capacidad crítica que es constitutiva de la persona deliberativa. En este punto, es crucial retomar la conexión interna que según Günther debe identificarse entre las dos dimensiones de la libertad comunicativa, que se corresponden con los dos roles que competen a la persona deliberativa. El reproche de culpabilidad se dirige a la persona de derecho, en tanto destinatario obligado al seguimiento de la norma. Pero este reproche sólo es legítimo bajo la condición de que la persona haya tenido la posibilidad de tomar parte, como ciudadano, en el procedimiento democrático en el cual se establece y se revisa la validez de la norma.

La imposición y la ejecución de la pena han de verse como la materialización del reproche sobre la persona del condenado por su déficit de lealtad comunicativa. Por esto, la materialización del reproche contra la persona de derecho no puede desvincularse de la atribución de la condición de ciudadano a esa persona, pues de lo contrario el reproche, como actitud reactiva, carece de base intersubjetiva. La paradoja del reproche expresado en la pena se encuentra en que el reproche constituye un reconocimiento cuyo sentido es la desaprobación. Que en esta desaprobación hay un reconocimiento se sigue necesariamente de la suposición de que el reproche y la pena deben ser merecidos, ${ }^{48}$ que es el núcleo de la exigencia de culpabilidad. La pena puede verse, como sugiere Walzer, como un honor negativo. ${ }^{49}$

La relación entre reconocimiento y ciudadanía es una relación fuerte. En una sociedad democrática donde impera el ideal de la autenticidad, la ciudadanía

\footnotetext{
${ }^{46}$ Strawson, Libertad y resentimiento, p. 63; Moore, Placing Blame, pp. 191-247.

47 Cfr. Hegel, Principios de la Filosofía del Derecho (Edhasa: Barcelona, 1998) p. 161: "La lesión que afecta al delincuente no es sólo justa en sí; por ser justa es al mismo tiempo su voluntad existente en sí, una existencia de su libertad, su derecho".

48 Walzer, Las esferas de la justicia (FCE: México, 1993) pp. 278-80.

49 ibid 282.
} 
está en el centro de una política de reconocimiento igualitario, que vuelve inviable la noción de honor propia de una sociedad jerárquicamente organizada. ${ }^{50} \mathrm{Si}$, en ese contexto, la legitimidad de la expresión institucional del reproche está condicionada por el mantenimiento de la vinculación del sujeto a la norma desautorizada, el condenado debe seguir siendo reconocido como ciudadano. Por eso, una privación de la calidad de ciudadano por el hecho de una condena a pena aflictiva, tal como está dispuesta en el artículo 17 de la Constitución chilena, hace imposible legitimar las consecuencias del reproche sobre la base de una actitud reactiva por una falta de lealtad comunicativa. Si la Constitución chilena niega la calidad de ciudadano al sujeto a quien se impone una pena privativa o restrictiva de libertad de duración superior a tres años, la Constitución hace inviable la construcción de un derecho penal del ciudadano. Y la alternativa a un derecho penal del ciudadano es, inevitablemente, un derecho penal del enemigo. ${ }^{51}$

La formulación de un reproche de culpabilidad que implica, sin embargo, la privación de la calidad de ciudadano constituye una contradicción realizativa (o "performativa"). Esa consecuencia jurídica implicada en el reproche niega un presupuesto del éxito ilocucionario del reproche en tanto acto de habla. Un reproche puede entenderse como un acto de habla normativo (o "regulativo"), definido por una pretensión de rectitud normativa. El hablante que formula un reproche presupone un horizonte normativo que lo vincula con el destinatario de su acto de habla. El reproche jurídico-penal, como acto de habla institucionalmente ligado, presupone la validez de la norma quebrantada por el sujeto a quien ello se reprocha como norma vinculante para éste. Bajo un estado democrático de derecho, esta condición sólo es posible en la medida en que la norma pueda seguir siendo reconducida al procedimiento en el cual todos los sujetos que pueden ser sus destinatarios puedan verse, a su vez, como sus autores.

El condenado debe seguir siendo ciudadano para que las consecuencias del reproche puedan justificarse como comunicativamente racionales.

Puede ser ilustrativo indagar en las implicaciones de la sugerencia contraria, o sea, la sugerencia de que la imposición de la pena es consistente con la privación de la ciudadanía. Esto aparece con claridad en Fichte, quien, sobre una base radicalmente contractualista de la justificación de la ley penal, entiende que el "contrato de ciudadanía" incorpora una condición elemental: "Todos los derechos positivos que posee el ciudadano sólo los posee a condición de que los derechos de todos los otros ciudadanos estén seguros ante él", en términos tales que "[t]odo delito excluye del Estado (el criminal se convierte en proscrito, es decir que su

\footnotetext{
50 Taylor, La ética de la autenticidad (Paidós: Barcelona, 1994) pp. 77-81.

51 Jakobs, "Criminalización en el estadio previo a la lesión de un bien jurídico", en Estudios de Derecho Penal (Civitas: Madrid, 1997) pp. 293-324; el mismo, "Derecho penal del ciudadano y derecho penal del enemigo", en Jakobs y Cancio Meliá, Derecho penal del enemigo (Civitas: Madrid, 2003) pp. 19-56.
} 
seguridad está tan poco garantizada como la de un pájaro, ex lex, hors de loı)" ${ }^{52}$ Pero lo importante es advertir qué consecuencias se siguen de la declaración de privación de derechos, que equivale a la exclusión absoluta del estado. En la concepción de Fichte, esto se da siempre que es imposible alcanzar el fin que persigue el ejercicio del poder estatal, que es asegurar las condiciones de seguridad recíproca, por una vía distinta de la exclusión del estado. A contrario, en la medida en que la seguridad pública no resulte amenazada, es posible no imponer la exclusión "de la que es en rigor merecedor todo delito", sobre la base de lo que Fichte denomina "contrato de expiación": "todos prometen a todos, en la medida en que es compatible con la seguridad pública, no excluirles del estado por sus delitos, sino permitirle expiar esta pena de otra manera". ${ }^{53}$

Pero no puede descartarse que en ciertos casos la sujeción al contrato de expiación resulte incompatible con el fin del estado. Según Fichte, esto se da en dos grupos de situaciones: primero, sin que se practique una prueba provisional orientada a la corrección del sujeto, ya sea porque se trata de un asesino (pues el asesinato intencional y premeditado es "el único crimen contra el que el esfuerzo por mejorar al criminal no ha ya a lugar") o porque el sujeto no quiere someterse a prueba (pues la expiación es un derecho renunciable); y segundo, tras haberse fracasado en esa prueba provisional. ${ }^{54}$ En una situación en que el vínculo entre el ciudadano y el estado se ha disuelto por resultar imposible garantizar la seguridad a través de la expiación, afirma Fichte, aquél ya no es ciudadano y éste ya no es estado, de modo que la situación está fuera del alcance del derecho. Aquí ya no hay lugar para la expiación ni, en general, para la pena, en términos tales que la intervención sobre el exonerado sólo puede concebirse como una medida de seguridad. ${ }^{55}$

La indagación es importante, si se vincula a la constatación, hecha por Jakobs, de que para Fichte "todo delincuente es de por sí un enemigo". ${ }^{56}$ Negar al autor la calidad de ciudadano implica definirlo como enemigo. La intervención sobre un individuo al cual se priva de la ciudadanía no puede entonces constituir derecho penal del ciudadano, sino sólo derecho penal del enemigo, o sea, "guerra refrenada". ${ }^{57} \mathrm{Si}$ la privación de libertad se impone bajo la negación de la calidad de ciudadano, ella no puede constituir una pena, que expresa un reproche entre sujetos vinculados, sino sólo una medida de seguridad, que presupone una actitud objetivante. Y la medida de seguridad sobre individuos definidos como peligrosos

\footnotetext{
52 Fichte, Fundamento del Derecho Natural (Centro de Estudios Constitucionales: Madrid, 1994) p. 316.

53 ibid 317.

54 ibid 330.

55 ibid 331-2.

${ }^{56}$ Jakobs, "Derecho penal del ciudadano y derecho penal del enemigo" p. 29.

57 ibid 42.
} 
es una de las notas definitorias de lo que se conoce como derecho penal del enemigo. ${ }^{58}$

Si lo anterior es correcto, las reacciones críticas frente a la actual irrupción y consolidación de un derecho penal del enemigo tendrían que resultar incomprensibles, quizá histéricas, para la comunidad jurídica chilena. ${ }^{59}$ Pues el derecho penal del enemigo, actualmente asociado a delitos terroristas, de narcotráfico y en general de criminalidad organizada, bajo la Constitución chilena se encuentra reconocido en un ámbito mucho más extenso: respecto de cualquier delito que tenga asignada una pena de privación o restricción de libertad superior a tres años.

\section{Privación de ciudadanía y privación de libertad}

El punto anterior hace posible redefinir el sentido político de la privación de libertad. En todo el ámbito en que su imposición conlleva la pérdida de la ciudadanía, se vuelve imposible concebirla como pena, pues la pena presupone el reproche de culpabilidad, y éste es incompatible con la negación del presupuesto elemental de la vinculación del sujeto a la norma, que es la ciudadanía. En este ámbito, por ende, la privación de libertad constituye una medida de seguridad, que implica que el estado asume una actitud objetivante frente al sujeto, representándose a éste como enemigo sobre el cual es necesario intervenir tácticamente.

Puesto que la privación estatal de libertad es inseparable de la institución carcelaria, la configuración de la primera como medida de seguridad tendría que reducir el carácter trasgresor que a veces parece adquirir el discurso crítico acerca de la segunda. Pues bajo la configuración de la privación de libertad como pena, o sea, bajo la exigencia de funcionalidad de la privación de libertad carcelaria a la expresión del reproche de culpabilidad, algunas de sus notas distintivas resultan difíciles de explicar. Desde ya, lo que Foucault denomina la "evidencia de la prisión", esto es, el hecho de que su existencia resulte algo no necesitado de justificación en las sociedades actuales, a pesar de que no es más que una de las tantas posibilidades para la organización de la pena. ${ }^{60}$ Que la prisión sea un dato evidente de la vida social se explica mucho mejor si su función consiste en modificar y/o neutralizar al enemigo peligroso respecto del cual sólo persiste la posibilidad de una orientación cognitiva. Pues la prisión no es sólo el lugar donde se verifica esa "detención legal", sino también una "empresa de modificación de

\footnotetext{
58 ibid 32.

59 Por ejemplo, Gracia Martín, "Consideraciones críticas sobre el actualmente denominado 'Derecho penal del enemigo", 07-02 Revista Electrónica de Ciencia Penal y Criminología (2005); Cancio Meliá, “¿«Derecho penal» del enemigo?”, en Jakobs y Cancio Meliá, Derecho penal del enemigo, pp. 57102.

${ }^{60}$ Foucault, Vigilary Castigar, p. 234.
} 
individuos". Pero sobretodo se hace manifiesto el sentido de la transformación del objeto de la privación de libertad que se opera en la prisión:

Pero esto implica que el aparato penitenciario, con todo el programa tecnológico de que se acompaña, efectúa una curiosa sustitución: realmente recibe un condenado de manos de la justicia; pero aquello sobre lo que debe aplicarse no es naturalmente la infracción, ni aun exactamente el infractor, sino un objeto un poco diferente, y definido por unas variables que al menos al principio no estaban tomadas en cuenta por la sentencia, por no ser pertinentes sino para una tecnología correctiva. Este personaje distinto, por quien el aparato penitenciario sustituye al infractor condenado, es el delincuente. ${ }^{61}$

Que en la prisión se opere esa transformación es enteramente consistente con la ruptura de la identidad jurídica del sujeto condenado que la privación de ciudadanía conlleva como consecuencia accesoria de la "pena" privativa de libertad. Sólo puede reprocharse una falta de lealtad comunicativa a un ciudadano, pero la consecuencia institucional del reproche conduce a que éste ya no lo sea. Frente a la discusión actual sobre la posibilidad de introducir una reforma legal que contemple una solución de three strikes and you're out, habría que decir que en el derecho chileno ya se contempla una solución mucho más radical: one strike and you're out!

Por último, la configuración de la privación de libertad en la prisión como una medida de seguridad vuelve comprensible el nexo funcional entre la privación de libertad tras la condena y la prisión preventiva durante el transcurso del proceso penal. Si la privación de libertad tras la condena es configurada institucionalmente como pena, o sea, es configurada como un modo adecuado de expresar reproche a la persona deliberativa por un déficit de lealtad comunicativa, la detención o prisión preventiva deviene difícilmente justificable. Pues si como sugiere Walzer, la pena es un honor (un reconocimiento) negativo, su imposición exige merecimiento, frente a lo cual

[1] as mujeres y los hombres detenidos [preventivamente] son castigados por razones incompatibles con nuestra noción común de lo que el castigo es y de cómo debería ser distribuido. Por consiguiente, la detención es un acto tiránico. ${ }^{62}$

Pero si la privación de libertad tras la condena se entiende como una medida de seguridad justificada prospectivamente, como intervención estratégica sobre un enemigo peligroso, la prisión preventiva parece resultar igualmente evidente o natural. Como "medida cautelar", la privación de libertad resulta indicada en la medida en que haya antecedentes suficientes sobre la peligrosidad del individuo. En este sentido, son suficientemente ilustrativas las reglas sobre prisión preventiva establecidas en el Código Procesal Penal: además de la exigencia

\footnotetext{
61 ibid 255.

${ }^{62}$ Walzer, Las esferas de la justicia, pp. 282-3.
} 
de antecedentes que justifiquen la existencia del delito investigado y de antecedentes que hagan presumir la participación del imputado, el artículo 141 sólo exige antecedentes que permitan considerar al tribunal "que la libertad del imputado es peligrosa para la seguridad de la sociedad". Desde este punto de vista, la función de la condena puede reducirse a constituir un momento de comprobación ulterior de la necesidad de intervención sobre el individuo peligroso, una vez que la prueba aportada hace posible descartar, con mayor certeza, que el individuo no haya ejecutado o intervenido en un hecho respecto del cual la privación de libertad es necesaria. Por lo demás, así cobra un sentido inequívoco la denominación del cese de la prisión preventiva como libertad provisional: la situación primaria que en el proceso penal corresponde al imputado no es de libertad sino de privación de libertad.

Lo anterior hace posible una redefinición de la concepción unilateral de la culpabilidad: la culpabilidad no fundamenta la pena, porque ésta no expresa un reproche, sino que es el criterio de reconocimiento de la necesidad de intervención preventivo-especial (y de reforzamiento de la conminación funcional a la prevención general negativa). Bajo una política de la privación de libertad como ésta, la exigencia de culpabilidad (formal) como condición necesaria de su imposición sólo puede cumplir una función de encubrimiento legitimante de un derecho penal de medidas de intervención preventivas orientadas a la neutralización del individuo peligroso. Pues allí donde la declaración de culpabilidad conduce a la privación de la calidad de ciudadano, éste es declarado, como dice Foucault, parte "de lo Otro", de aquello que es extraño pero interno al mismo tiempo, por lo cual debe ser expulsado, pero a través del encierro.

Sobre esta base, resulta insuficiente poner en cuestión la legitimidad de la regulación constitucional de la prisión preventiva, en relación con la regla del artículo $19 \mathrm{~N}^{\circ} 7 \mathrm{e}$ ), que establece la procedencia de la libertad provisional a menos que la detención o prisión preventiva sea "[...] necesaria para la seguridad del ofendido o de la sociedad", sosteniendo que ella "obedece, propiamente, a la de un sistema inquisitivo". ${ }^{63} \mathrm{El}$ problema no se encuentra (sólo) en la sustitución legal de un sistema de procedimiento penal inquisitivo por uno acusatorio o adversativo. Antes bien, la regla resulta plenamente consistente con las bases del ejercicio de la potestad punitiva fijadas en la Constitución chilena, que son las de un derecho penal del enemigo.

La consecuencia de esto es la disolución de un sistema de la doble vía, esto es, de un sistema de reacciones basado en la diferenciación entre penas y medidas de seguridad. Si la intervención formalmente denominada "pena" supone un tratamiento objetivante del individuo que padece su imposición y ejecución, la distinción entre penas y medidas se vuelve irrelevante. A este respecto, es sintomático que en la doctrina penal chilena, a partir de una definición de la

${ }^{63}$ Cfr. Horvitz y López, Derecho Procesal Penal Chileno (Editorial Jurídica: Santiago, 2002) tomo I, p. 392. 
función de la pena como autoconstatación del estado, como "instrumento de aseguramiento del Estado", ya se haya remarcado que "la ficticia frontera entre pena y medida" ha quedado superada como "producto de una determinada etapa histórica". ${ }^{4}$

\section{La constitución del derecho penal del enemigo}

Cuando se discute la relación entre constitución y derecho penal, generalmente se plantean consideraciones acerca de los límites que la constitución impone al ejercicio de la potestad punitiva. ${ }^{65}$ En relación con la Constitución chilena, las referencias tienden a ser hechas a la proscripción de presunciones de derecho en materia penal (artículo $19 \mathrm{~N}^{\circ} 3$ inc. $6^{\circ}$ ), en la cual se encuentra reconocido el principio de culpabilidad, a las exigencias asociadas al principio de legalidad (artículo $19 \mathrm{~N}^{\circ} 3$ incisos $7^{\circ}$ y $8^{\circ}$ ) y a la posibilidad de fundamentar un punto de apoyo institucional para el principio de proporcionalidad (por ejemplo, en el artículo $19 \mathrm{~N}^{\circ}$ 26). Típicamente, estas referencias presuponen una concepción de la constitución como un complejo de restricciones sustantivas y procedimentales a la potestad de decisión de los órganos del estado, y en este ámbito, sobretodo a la potestad del legislador. ${ }^{66}$

Esta concepción de la función normativa de la constitución puede calificarse de regulativa. La noción de los derechos fundamentales como derechos del ciudadano contra el estado, por ejemplo, parece suponer una concepción prescriptiva y, por ende, regulativa, de las normas constitucionales que establecen esos derechos. Pero es posible sugerir una concepción alternativa de la constitución, bajo la cual su función aparece como genuinamente constitutiva. ${ }^{67} \mathrm{La}$ función de la constitución, en este sentido, es constituir la comunidad política. La

\footnotetext{
${ }^{64}$ Bustos, "Pena y Estado", en Bases críticas de un nuevo derecho penal (ConoSur: Santiago, 1995) pp. 127-62, 162.

65 Paradigmáticamente, Ferrajoli, Derecho y Razón (Trotta: Madrid, 1995).

${ }^{66}$ Sobre los peligros de esta forma de entender la relación entre derechos fundamentales y ejercicio de la potestad punitiva, dada una modificación del paradigma de comprensión de los derechos fundamentales, Mañalich, "La prohibición de infraprotección como principio de fundamentación de normas punitivas. ¿Protección de los derechos fundamentales mediante el derecho penal?”, en 11 Derecho y Humanidades (Santiago, 2005) pp. 245-58.

${ }^{67} \mathrm{La}$ distinción entre reglas regulativas y reglas constitutivas se encuentra en Searle, Speech Acts (Cambridge University Press: Cambridge, 1969) pp. 33-42. Con esto no se sugiere que, en general, el derecho pueda ser descrito adecuadamente como un sistema de reglas constitutivas. Es claro que en el derecho es posible identificar ciertas reglas que se entienden como puramente regulativas (p. ej., la norma que prohíbe matar a otro) y otras que se entienden como constitutivas (p. ej., las reglas que definen bajo qué condiciones se tiene propiedad sobre un objeto). En relación con el derecho, la cuestión consiste, más bien, en determinar si el conjunto de reglas puede ser entendido como un sistema constitutivo o como un sistema regulativo. A este respecto, la tesis de Atria es que los sistemas jurídicos modernos sólo pueden ser entendidos como instituciones regulativas (y no como instituciones autónomas, como lo serían los juegos), esto es, que constituyen para regular. Véase Atria, On Law and Legal Reasoning (Hart: Oregon, 2001) pp. 1-61.
} 
implicación de esta concepción es que lo que define a lo constitutivo es que la práctica constituida no puede preexistir a las condiciones de su constitución. Desde este punto de vista, la pretensión primaria (de carácter normativo) que subyacería a una constitución es fijar las bases sobre las cuales la vida política es posible, por ejemplo, incluyendo cierta concepción acerca de la identidad moral de quienes toman parte en esa comunidad política.

Esta concepción como constitutiva-de-lo-político de la función de la constitución puede contribuir a la reflexión acerca del modo en que se despliega la política constitucionalmente estructurada. Esto no puede ser distinto para cada una de las dimensiones de la política, incluida la política criminal. En la Constitución chilena se encuentra expresada una predisposición de la orientación de la política criminal. Y esta predisposición político-criminal se ajusta a un modelo de derecho penal del enemigo. Que todo sujeto condenado a una pena aflictiva sea privado de su ciudadanía hace posible una configuración estrictamente unilateral de la política criminal. La situación actual de las cárceles chilenas se vuelve explicable, pues la dignidad allí negada es la dignidad que los ciudadanos nos atribuimos recíprocamente.

Ya se han revisado dos bases constitucionales del derecho penal del enemigo. Una es la privación de ciudadanía asociada a la imposición de cualquier pena privativa o restrictiva de libertad cuya duración exceda de tres años. Que el artículo 16 de la Constitución establezca la suspensión del derecho de sufragio como consecuencia del procesamiento "por un delito que merezca pena aflictiva" sólo confirma el programa de política criminal así constituido. La otra es la legitimación de la prisión preventiva respecto de todas las situaciones en que la medida resulte indicada en atención a la salvaguarda de la seguridad de la sociedad. La primera se encuentra en el Capítulo II de la Constitución, que establece las reglas sobre nacionalidad y ciudadanía; la segunda, en el Capítulo III, sobre derechos (y deberes) fundamentales. La consideración de ambas confiere sentido a ciertas tendencias de la discusión de política criminal actual: que algunos parlamentarios hayan sugerido la posibilidad de introducir una reforma que estableciera la unanimidad del tribunal colegiado como condición del cese de la prisión preventiva (libertad "provisional") se explica sin dificultades si se asume que la política criminal chilena está constituida sobre la base de un modelo de derecho penal del enemigo.

La tercera base constitucional se encuentra en el artículo 9, que confiere un estatus especial los hechos constitutivos de conductas terroristas, prejuzgando su puniblidad (en términos regulativos, estableciendo un mandato de punición), y que conlleva un tratamiento más severo, que entre otras cosas conduce a la privación de la ciudadanía en caso de condena (aun cuando la pena impuesta no sea aflictiva). Que en el último tiempo algunos parlamentarios plantearan la posibilidad de someter a este mismo régimen toda concesión del cese de la prisión preventiva es indicativo del programa político subyacente: todo (presunto) delincuente 
debería ser tratado como terrorista, en circunstancias que actualmente el terrorista aparece como el enemigo por definición. ${ }^{68}$

En relación con lo anterior, puede ser ilustrativo considerar una de las reformas a la Constitución aprobadas recientemente en el Congreso. Se trata, precisamente, de una modificación del artículo 17, que establece la pérdida de la ciudadanía por el evento de una condena por determinada clase de delitos. La reforma modifica el inciso $2^{\circ}$, relativo a las condiciones bajo las cuales un sujeto puede recuperar la condición de ciudadano tras haber sido privado de ella, estableciendo un régimen general más favorable que el anterior. En efecto, la situación previa a la reforma consistía en una exigencia de rehabilitación por el Senado, respecto de todo individuo que hubiese sido privado de la ciudadanía por haber sido condenado a pena aflictiva, y en una exigencia (más estricta) de rehabilitación mediante ley de quórum calificado, aplicable en los casos de privación de ciudadanía por condena por delito terrorista (independientemente de la clase y cuantía de la pena impuesta). La reforma modifica la fórmula de rehabilitación general, previendo la recuperación de la ciudadanía "en conformidad con la ley" ("una vez extinguida [la] responsabilidad penal"). A primera vista, esta reforma debería ser celebrada, pues implica un relajamiento de las condiciones de la recuperación. Bajo la nueva regulación constitucional la ley podría, por ejemplo, establecer un procedimiento administrativo de recuperación de la ciudadanía. Pero la celebración no puede ser mantenida. La reforma también relaja las condiciones para la recuperación de la ciudadanía perdida por condena por delito terrorista, exigiendo la rehabilitación por el Senado ("una vez cumplida la condena"). La reforma equipara a este caso, empero, el de los sujetos privados de ciudadanía por condenas por delitos de tráfico de estupefacientes ("y que hubieren merecido, además, pena aflictiva"). Esta extensión (parcial) de las consecuencias asociadas a la punibilidad por delito terrorista a la punibilidad por tráfico de estupefacientes muestra el programa expansivo que subyace a la definición constitucional de las condiciones de un derecho penal del enemigo.

Aquí no interesa tomar posición sobre la legitimidad de reconocer un espacio marginal donde pueda hacerse efectivo un modelo de derecho penal del enemigo, o sea, de un sistema de intervención estatal sobre individuos definidos como enemigos. Se trata de registrar algo mucho menos marginal: la Constitución chilena sienta las bases de un modelo de derecho penal del enemigo como modelo general de ejercicio de la potestad punitiva. Esto hace posible aprender una lección de estos tiempos de neo-constitucionalismo: si el derecho penal corresponde a la descripción de un derecho constitucional aplicado, el derecho penal del enemigo también puede serlo.

\footnotetext{
${ }^{68}$ Véase Jakobs, "Derecho penal del ciudadano y derecho penal del enemigo", pp. 41-3.
} 